\section{A CASE OF SELF-MUTILATION.}

BY

DOUGLAS J. A. KERR, M.B., Ch.B.Ed., ASSISTANT, FORENSIC MEDICINE DEPARTMENT, EDINBURGH UNIVERSITY.

THE following report is of considerable medico-legal interest, and though cases of self-mutilation occasionally occur, chiefly in asylums, the accompanying illustrations are probably unique in the annals of forensic medicine.

The deceased was a healthy man until two years before his death, when he contracted rheumatism, which prevented him from working. Since then he had been unemployed, and his landlady noticed that he was becoming strange in his manner.

About 10.30 one morning he left the house, saying he would return at midday for his dinner; he appeared

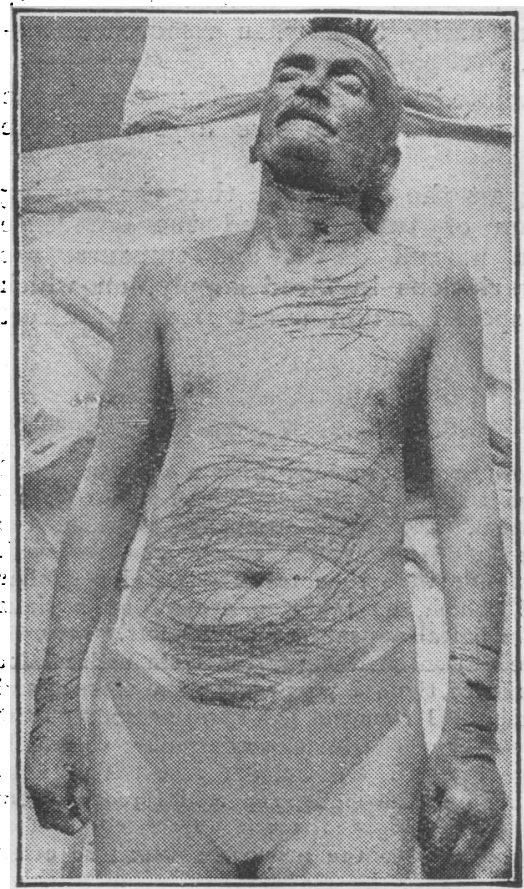

Ventral aspect. to be depressed, and was under the delusion that he

muscular tissue. A similar wound was situated just below the main wound. In addition to these wounds the following cuts were found:

Forehead 5-extending across the greater part of the forehead.

Chin and neck 27-two extending round the right side of tho neck as far as the mid-line behind. Chest 72 .

Left axilla and side of chest 27.

Ábdomen 168 .

Left arm: Palmar surface-palm 24, fingers 15, wrist 4 forearm 6. Dorsal surface-hand 2, fingers 13, wrist 2 forearm 6.

Right arm: Palmar surface-palm 26, wrist 12. Dersal surface-hand 2, wrist 10 , fingers 21 .

Scrotum : Six faint scratches on the most dependent part.

The wounds had been inflicted with a somewhat blunt penknife having a blade $1 \frac{3}{4} \mathrm{in}$. long, which was found in the field near the deceased.

\section{Comment.}

The case presents many points of medico-legal interest. The number and character of the wounds are typical of self-infliction and mental derangement. Similar cases have

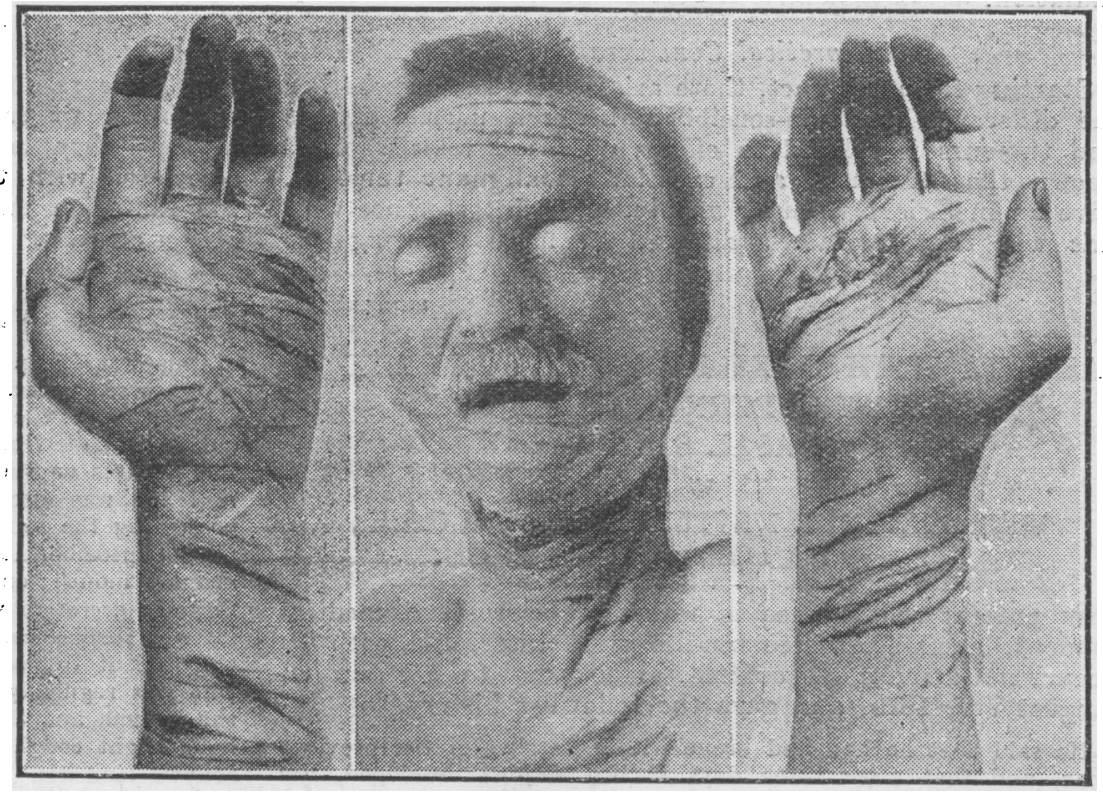

Left hand.
Right hand. had killed his sister. He was not seen for two days, when he was found lying in a field on the outskirts of Edinburgh; his clothes, with the exception of his trousers, socks, and boots, had been removed, and he was seen to have numerous wounds on the head, throat, and body. He was taken in an ambulance to hospital, where he arrived in a very collapsed condition, almost pulseless. He was conscious, and understood directions, but was too weak to talk. The wound in his throat was septic and crawling with maggots, but not bleeding. He died eight hours later.

\section{Post-mortem Examination.}

Lividity was well marked. The internal organs and brain were normal in appearance. All the organs were plentifully supplied with blood, and death had not taken place from haemorrhage. The body showed over four hundred and forty different cuts, chiefly superficial, though in a number of instances, such as on the back of the left arm, on the fingers and throat, the underlying muscles were divided.

The main wound was in the throat; it started just below the lobe of the left ear, and passing immediately above the thyroid cartilage it ended at a point on the lower jaw midway between the angle and the symphysis menti. The incision had severed the sterno-hyoid and omo-hyoid muscles on each side, but the main vessels and air passages were uninjured The wound was septic and crawling with maggots. Immediately above the main wound, at its commencement on the left side and parallel to it, was a smaller wound, $2 \mathrm{in}$. in length, which penetrated the been recorded, one of the most striking being that noted by Maschka (Prag. med. Woch., 1888), and referred to in Dixon Mann's Forensic Medicine. In this case a man, who was an inmate of an asylum, inflicted 285 punctured wounds on himself, 200 being on the left side of the chest, 50 on the left forearm, and 28 on the right forearm.

In the case here recorded, in addition to the injuries on the trunk and arms, the forehead, chin, and cheeks had been extensivelv slashed. Of special interest aro the cuts on the palmar aspect of both hands. This is a most unusual place for self-inflicted injuries. Incised wounds on the palms and fingers are regarded as characteristic of injuries resulting from an attempt to ward off an assailant armed with a knife or razor, by seizing tho blade with the hands. Had this case shown only such wounds on the hands and the wounds on the throat, a strong suspicion of homicide would have arisen.

The cause of death is also interesting. No vital structure was injured, and the loss of blood had been slight, as was shown by the well marked post-mortem lividity and the condition of the internal organs. Judging from the condition of the wound in the throat and the time of his disappearance, the man had apparently been lying out in the field, after the wounds had been inflicted, for two days and nights, clad only in a pair of trousers. This, together with the general healthy state of the organs and absence of disease, justified the inference that death had resulted from exposure and shock.

I am indebted to Professor Littlejohn and Professor Lorrain Smith for permission to publish this case. 